\title{
USING TAGUCHI METHOD TO PREDICT THESELF-COMPACTING RUBBERIZED CONCRETE MECHANICAL AND FRESH PROPERTIES
}

\author{
M.A. Emara' ${ }^{1}$, Fatma.M. Eid ${ }^{2}$, A.A. Nasser ${ }^{3}$, M.A. Safaan ${ }^{4}$ \\ ${ }^{l}$ Civil Engineering Department, Faculty of Engineering, Minoufia University, Gamal Abdul-Nasser Street, Minoufia, Egypt \\ ${ }^{2}$ Civil Engineering Department, Faculty of Engineering, Minoufia University, Gamal Abdul-Nasser Street, Minoufia, Egypt \\ ${ }^{3}$ Civil Engineering Department, Faculty of Engineering, Minoufia University, Gamal Abdul-Nasser Street, Minoufia, Egypt \\ ${ }^{4}$ Civil Engineering Department, Faculty of Engineering, Minoufia University, Gamal Abdul-Nasser Street, Minoufia, Egypt
}

\begin{abstract}
The effect and optimization of using self-compacting rubberized concrete was studied. Design of experiment using Taguchi method was performed via orthogonal array to accommodate four factors with four levels. These factors were the percentage of fine rubber, coarse rubber, fly ash and viscocrete in the concrete mix. The signaltonoise ratio was used as well as the analysis of variance (ANOVA) to evaluate the characteristics performance of self-compacting rubberized concrete (SCRC). Rubberized concrete can be improved using the concrete proportioned as selfcompacting concrete. The results indicated that a reduction in compressive strength increasing rubber content but there was an increase in impact resistance. However, the replacement of 10\% of coarse aggregate with coarserubber gave more strength than that of zero rubber mix by $124 \%$ at 90 days. Replacement of $20 \%$ of both fine and coarse aggregates with fine and coarse rubber respectively, increased impact resistance by $453 \%$ compared to the corresponding SCRC control mix.
\end{abstract}

Keywords: Rubber; Recycling; Self-compacting; Taguchi Method; ANOVA.

\section{INTRODUCTION}

Self-Compacting Concrete (SCC) is a high performance developed concrete [1] described as a revolution in concrete manufacture in the last two decades.SCC has high impact on economic and environmental sustainability in the construction industry [2]. It has many advantages such as increased productivity rates, decreased manpower, and noise elimination [3]. SCC is able to fully self-compact under its own weight compared to plain concrete. It has high flowability and reduced blocking in reinforced areas and high segregation resistance as well as low permeability and high compressive strength [4].

The volume of polymeric solid waste like rubber tires is increasing. Rubber tires waste becomes an environmental problem due to its non-biodegradable nature. Up to now a small part is recycled and millions of tires are just stockpiled; land filled or buried and used as fuel in many industries. Recycling of vehicle tires as aggregate alternative to produce a new type of concrete is an innovative option with environmental and economic benefits [5].

Many researchers have therefore used rubber particles as aggregates in concrete production to eliminate poor deformation capacity, low tensile strength, and improve energy absorption capacity. Aggregate rubber particles enhanced deformation and energy absorption capacities while they decreased workability and mechanical properties [6]. Self-compacting rubberized concrete (SCRC) was produced to diminish the negative effect of rubber aggregate on the mechanical properties and workability of concrete [7].SCC has high powder content, so its microstructure is very compacted and dense. This compacted microstructure results in high compressive strength and brittle modes of failure. Therefore, (SCRC) composites are used in requiring deformable applications, which is difficult to reach in SCC application using environmental friendly aggregates.

\section{AIM OF WORK}

In the current research fresh and harden properties of (SCRC) were studied using Taguchi method. 16 concrete mixes were designed with the same water/powder ratio W/P (P= cement+ fly ash). Self-compacting properties and mechanical behavior are discussed.

\section{DESIGN METHODOLOGY}

Parameter design of Taguchi method is an optimizing powerful tool to enhance performance of the product. Optimization quality characteristic minimizes Sensitivity to Noise(S/N) (uncontrollable) factors. In this study, four control factors were chosen with four levels shown in table (1). 
Table 1: Control Factors of Experimental Work

\begin{tabular}{|c|c|c|c|c|}
\hline \multirow[t]{3}{*}{ Level } & \multicolumn{4}{|l|}{ Factors } \\
\hline & $\mathrm{A}$ & B & $\mathrm{C}$ & $\mathrm{D}$ \\
\hline & $\begin{array}{l}\text { Replacement of fine } \\
\text { aggregates by fine } \\
\text { rubber }\end{array}$ & $\begin{array}{l}\text { Replacement of coarse } \\
\text { aggregates by coarse } \\
\text { rubber }\end{array}$ & $\begin{array}{l}\text { Fly-ash } \\
\text { (cement \%) }\end{array}$ & Viscocrete(cement \%) \\
\hline 1 & $0 \%$ & $0 \%$ & $20 \%$ & $2.00 \%$ \\
\hline 2 & $10 \%$ & $10 \%$ & $25 \%$ & $2.25 \%$ \\
\hline 3 & $15 \%$ & $15 \%$ & $30 \%$ & $2.50 \%$ \\
\hline 4 & $20 \%$ & $20 \%$ & $35 \%$ & $2.75 \%$ \\
\hline
\end{tabular}

\subsection{Design of Experiment}

Design of the experiment based on orthogonal array. The orthogonal array has a fractional design. It was obtained using selected factors with different levels of L16 array. It has 16 rows and 4 columns. Individual row represents an experimental trial condition. The column assists a product parameter. The main effects can be estimated. Each column has numbers, that indicate the levels of used factors (A, B, C and D). Taguchi Orthogonal Array Design is L16 $(4 * * 4)$. Factors are 4. Runs are $16[9,10,11]$.

\subsection{Taguchi's Orthogonal Array Approach of Experimental Design}

Taguchi's target is developing products that achieve the target value on a consistent basis. The variation around the target value should be minimized. In other words, quality is achieved by minimizing the deviation from the target. Factors and levels are illustrated in Table (1); the mixes are given in Table (2). Factor A is replacement of fine aggregate by fine rubber $(1 \mathrm{~mm})$ (replaced by $0,10,15$ and $20 \%$ ). Factor B is replacement of coarse aggregate by coarse rubber $(5 \mathrm{~mm})$ (replaced by $0,10,15$ and $20 \%$ ). Factor $\mathrm{C}$ is addition of fly ash as a ratio of cement (added by 20, 25, 30 , and $35 \%$ ). Factor D is using super plasticizer (viscocrete) as a ratio of cement $(2.00,2.25,2.50$ and $2.75 \%)$ [11].

Table 2: Experimental Test Design of Control Factors with factor levels

\begin{tabular}{|l|l|l|l|l|}
\hline \multirow{3}{*}{ Exp. No. } & \multicolumn{4}{|l|}{ Factors } \\
\cline { 2 - 5 } & \% Replacement by volume of aggregate & \multicolumn{2}{l|}{ Addition(\% wt of cement) } \\
\cline { 2 - 5 } & Fine rubber & Coarse rubber & Fly ash & viscocrete \\
\hline 1 & 0 & 0 & 20 & 2.00 \\
\hline 2 & 0 & 10 & 25 & 2.25 \\
\hline 3 & 0 & 15 & 30 & 2.50 \\
\hline 4 & 0 & 20 & 35 & 2.75 \\
\hline 5 & 10 & 0 & 25 & 2.50 \\
\hline 6 & 10 & 10 & 20 & 2.75 \\
\hline 7 & 10 & 15 & 35 & 2.00 \\
\hline 8 & 10 & 20 & 30 & 2.25 \\
\hline 9 & 15 & 0 & 30 & 2.75 \\
\hline 10 & 15 & 10 & 35 & 2.50 \\
\hline 11 & 15 & 15 & 20 & 2.25 \\
\hline 12 & 15 & 20 & 25 & 2.00 \\
\hline 13 & 20 & 0 & 35 & 2.25 \\
\hline 14 & 20 & 10 & 30 & 2.00 \\
\hline 15 & 20 & 15 & 25 & 2.75 \\
\hline 16 & 20 & 20 & 20 & 2.50 \\
\hline
\end{tabular}

\section{MATERIALS AND METHODS}

\subsection{Materials}

All test specimens were fabricated using locally available materials.

4.1.1. Cement:a locally produced ordinary Portland cement $(42.5 \mathrm{~N})$ produced by Lafarge Company meeting the requirement of E.S. 373/2003 was used with constant content $(400 \mathrm{~kg} / \mathrm{m} 3)$ for all mixes.

4.1.2. Fly ash:produced by SikaEgypt company fly ash type $\mathrm{P}$ (El Obour factory) was used as addition to cement.

4.1.3. Fine Aggregate: The sand was local siliceous sand with specific gravity 2.64 . 
4.1.5. Coarse Aggregate: used was natural limestone with $\max$ size of $12 \mathrm{~mm}$ to achieve the requirement of selfcompacting concrete.

4.1.6. Super plasticizer:a high range water reducer without retarding was used. (Sikaviscocrete 3425) was used as a demand for producing SCC. It meets the requirements for superplasticizers according to ASTM-C- 494 Types Gand F and BS EN 934 part 2: 2001.

4.1.7. Fine rubber aggregate:the fine crumb rubber used in this research is produced by MARSO factory at 10th
Ramadan city-Egypt with size of $(1 \mathrm{~mm})$ and was partially replaced (by volume) of fine aggregate.

4.1.8. Coarse rubber aggregate:the coarse rubber used in this research is produced by MARSO factory at 10th of Ramadan city-Egypt with one size of $(5 \mathrm{mms})$ and was used as a partial replacement (by volume) of coarse aggregate.

4.1.9. Water:fresh tap water was used with water /binder ratio $\mathrm{w} / \mathrm{b}=0.37$.

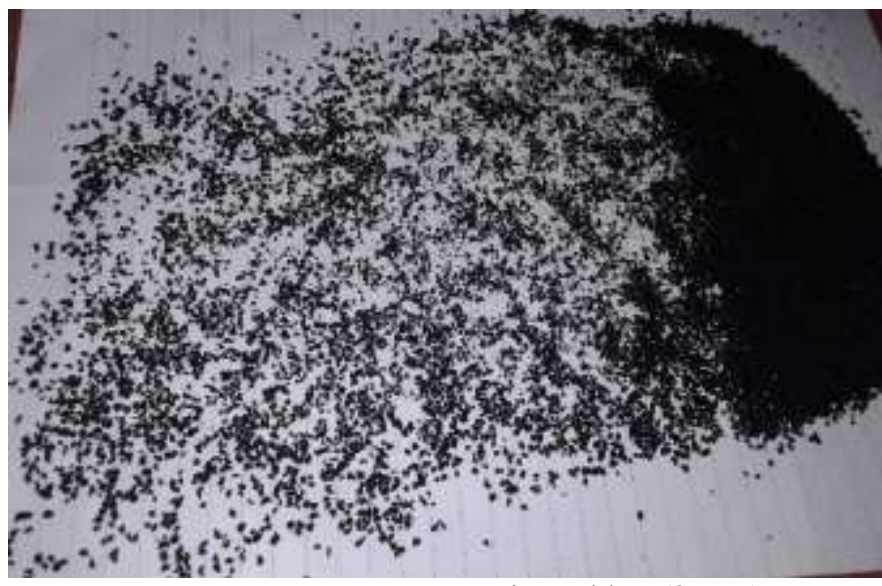

Fine rubber $(2 \mathrm{~mm})$

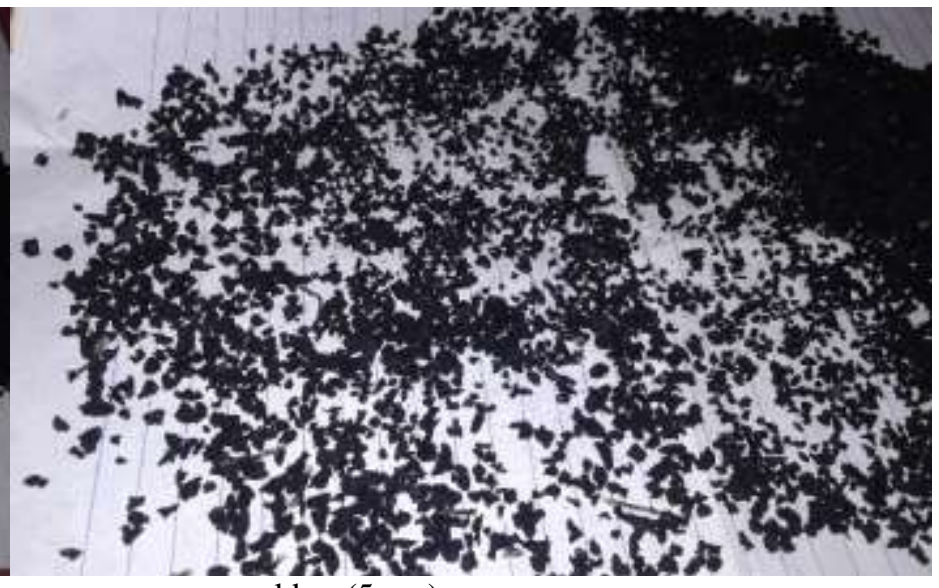

coarse rubber $(5 \mathrm{~mm})$

Fig 1: Fine and coarse rubber

\subsection{Mix Contents and Procedure}

4.2.1 Mix contents: The cement content was $400 \mathrm{~kg} / \mathrm{m}^{3}$ for this study with water/binder* ratio of 0.37 and the mix proportion ratio (of weight) for cement: sand: dolomite was 1:2.125:2.125 respectively.

*binder $=$ cement + fly ash

4.2.2 Mixing procedure was carried out in three stages; dry mix for 2 min, adding $75 \%$ of (water+S.P) and mixing for 2 min and a final mix for not less than 3 min after adding the remaining amount of (water+S.P). Subsequently, the fresh properties of SCRC mixes; Flowability and Passing-ability tests using slump flow, T50 test, V-Funnel and J-Ring) were determined. Concrete specimens were cast in standard steel molds. After $24 \mathrm{~h}$ from mixing, all the specimens were demolded and cured in wet canvas for 7 days.

\subsection{Tests}

\subsubsection{Fresh Tests}

Fresh concrete tests were experimented according to EFNARC committee (European Federation for Specialist Construction Chemicals and ConcreteSystems) procedure recommendation [13]. See figure (2).

\subsubsection{Slump Flow Test}

Slump flow value represents the flow-ability of fresh concrete mix. It can specify self-compacting concretes, as a check of fresh concrete consistence that meet specification [8] as shown in figure (2).

\subsubsection{V-Funnel}

V-funnel test was performed in a shaped funnel filled with fresh concrete. Time taken for the concrete to flow out the funnel is recorded as the $\mathrm{V}$-funnel flow time as shown in fig. (2).

\subsubsection{Hardened SCRC}

\subsubsection{Compressive Strength Test}

Compressive strength test was carried out on $15^{*} 15^{*} 15 \mathrm{~cm}$ cubes and according to ASTM C39-86. The capacity of the compression machine used is $2000 \mathrm{KN}$.

\subsubsection{Impact Test}

Beams $10 * 10 * 50 \mathrm{~cm}$ were prepared for this test. The impact resistance was assessed by measuring the ability of concrete 
specimens to withstand repeated blows of a free failing load $(3 \mathrm{~kg})$ at a constant travelling height of $40 \mathrm{~cm}$ above the midpoint of the tested concrete beam which was supported on two ends. The load was then left to fall freely on the top side of the concrete beam and the number of impact blows to cause failure was recorded $[14,15,16]$.

Figure (3) shows the hardened tests set up.

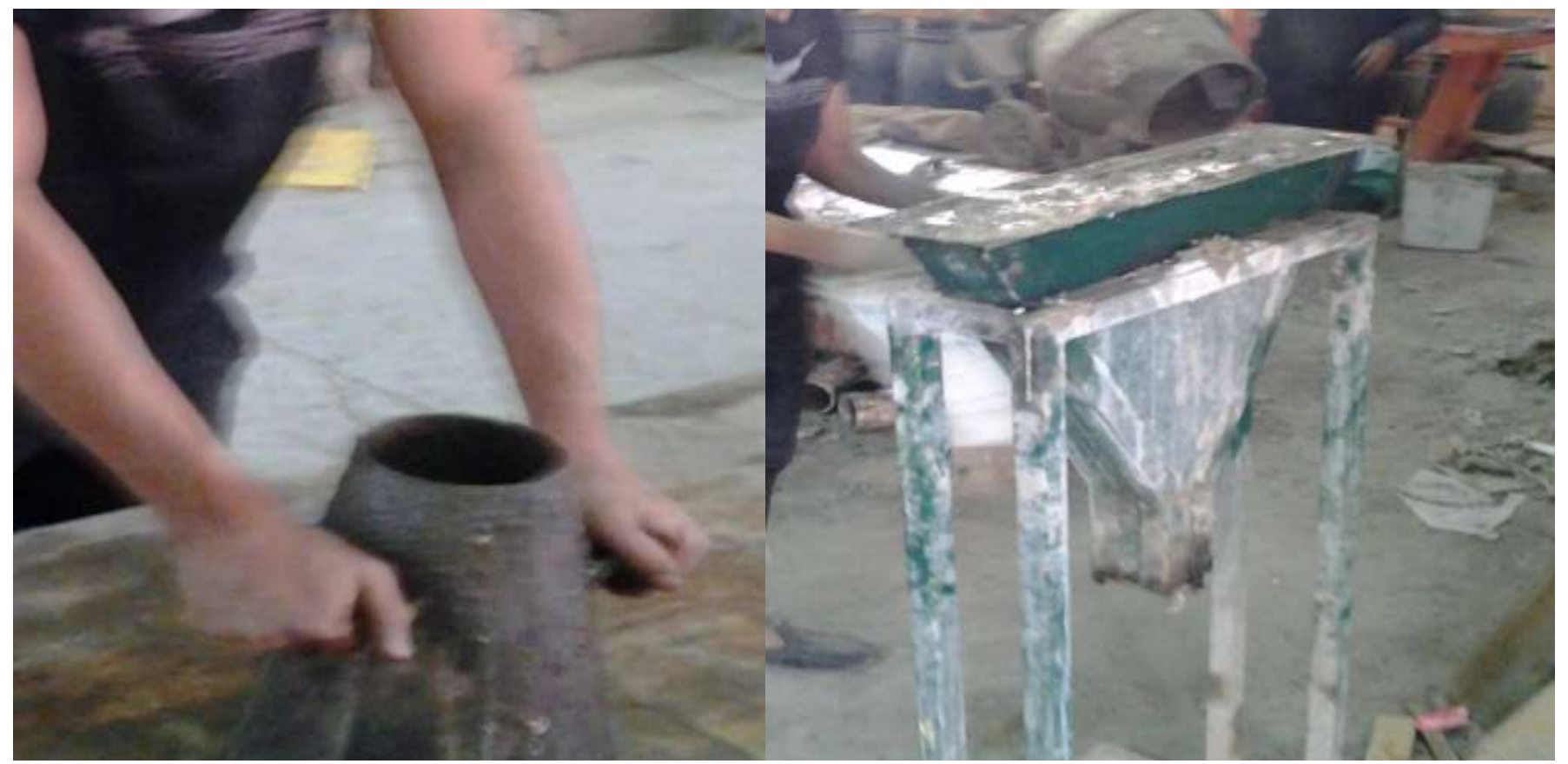

Slump flow test V-Funnel test

Fig 2: fresh tests

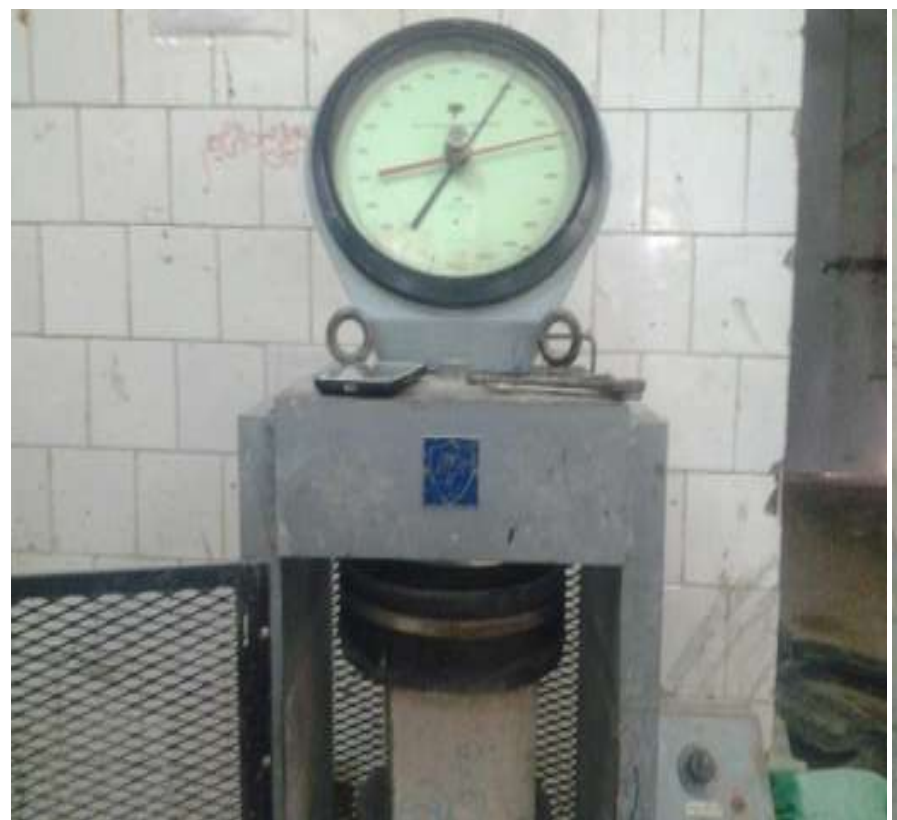

Compression test

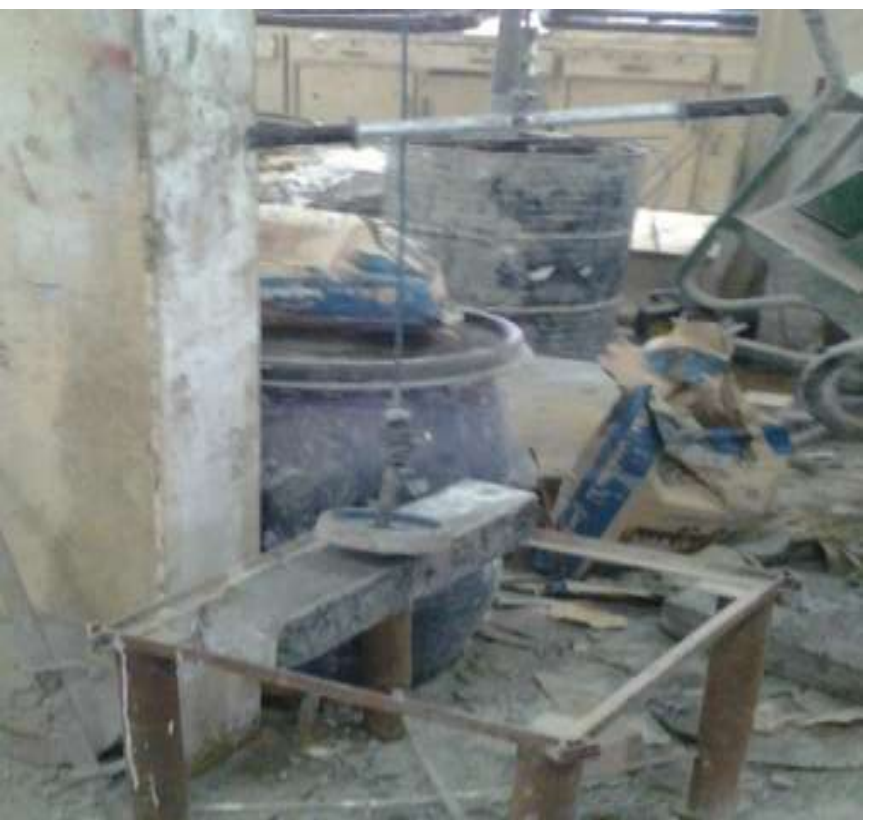

impact test

Fig 3: hardened tests

\section{RESULTS}

\subsection{Fresh Properties}

Experimental test results of fresh properties for SCRC are shown in table (3). 
Table 3: Experimental Test Results of Fresh Properties

\begin{tabular}{|l|l|l|l|l|l|}
\hline Mix. No. & Slump $(\mathrm{mm})$ & V-funnel(sec.) & Mix. No. & Slump $(\mathrm{mm})$ & V-funnel (sec.) \\
\hline 1 & 723 & 3.65 & 9 & 675 & 13.94 \\
\hline 2 & 735 & 3.79 & 10 & 690 & 7.2 \\
\hline 3 & 755 & 3.56 & 11 & 550 & 18.25 \\
\hline 4 & 720 & 6.47 & 12 & 585 & 14.97 \\
\hline 5 & 710 & 7.81 & 13 & 665 & 6.16 \\
\hline 6 & 740 & 5.89 & 14 & 630 & 11.03 \\
\hline 7 & 715 & 6.71 & 15 & 605 & 17.53 \\
\hline 8 & 645 & 5.72 & 16 & 560 & 9.22 \\
\hline
\end{tabular}

\subsection{Hardened Properties}

Experimental test results of compressive strength for SCRC are shown in table (4). Table (5) shows test results for impact resistance which represented by numbers of blows.

Table 4: Compressive Strength Test Results (Hardened Properties)

\begin{tabular}{|c|c|c|c|c|c|c|c|}
\hline \multirow{2}{*}{$\begin{array}{l}\text { Mix. } \\
\text { No. }\end{array}$} & \multicolumn{3}{|c|}{ Compressive strength (Mpa) } & \multirow{2}{*}{$\begin{array}{l}\text { Mix. } \\
\text { No. }\end{array}$} & \multicolumn{3}{|c|}{ Compressive strength (Mpa) } \\
\hline & 7days & 28days & 90days & & 7days & 28days & 90days \\
\hline 1 & 33.2 & 47.7 & 52.0 & 9 & 22.1 & 31.6 & 44.5 \\
\hline 2 & 40.3 & 53.3 & 64.4 & 10 & 21.3 & 32.9 & 37.3 \\
\hline 3 & 27.6 & 37.7 & 44.4 & 11 & 20.4 & 24.8 & 32.2 \\
\hline 4 & 21.6 & 347 & 456 & 12 & 19.0 & 24.3 & 29.0 \\
\hline 5 & 28.4 & 421 & 483 & 13 & 23.0 & 38.4 & 32.2 \\
\hline 6 & 23.9 & 35.8 & 43.9 & 14 & 23.9 & 25.7 & 33.6 \\
\hline 7 & 21.9 & 33.2 & 41.2 & 15 & 20.8 & 24.8 & 30.2 \\
\hline 8 & 20.2 & 26.0 & 38.3 & 16 & 18.3 & 20.2 & 29.8 \\
\hline
\end{tabular}

Table 5: Impact Test Results.

\begin{tabular}{|l|l|l|l|}
\hline \multirow{2}{*}{$\begin{array}{l}\text { No. } \\
\text { No. }\end{array}$} & $\begin{array}{l}\text { Impact } \\
\text { (blows) }\end{array}$ & \multirow{2}{*}{$\begin{array}{l}\text { Mix. } \\
\text { No. }\end{array}$} & $\begin{array}{l}\text { Impact } \\
\text { (blows) }\end{array}$ \\
\cline { 2 - 4 } & 28 days & & 28 days \\
\hline 1 & 17 & $\mathbf{9}$ & 23 \\
\hline 2 & 13 & $\mathbf{1 0}$ & 21 \\
\hline 3 & 15 & $\mathbf{1 1}$ & 31 \\
\hline 4 & 15 & $\mathbf{1 2}$ & 31 \\
\hline 5 & 29 & $\mathbf{1 3}$ & 35 \\
\hline 6 & 23 & $\mathbf{1 4}$ & 54 \\
\hline 7 & 22 & $\mathbf{1 5}$ & 55 \\
\hline 8 & 22 & $\mathbf{1 6}$ & 77 \\
\hline
\end{tabular}

\section{ANALYSIS AND DISCUSSION}

Design of experiment data analysis was used to calculate the mean response function. The response variation in Taguchi technique is tested using an appropriately chosen $\mathrm{S} / \mathrm{N}$ ratio. Signal to Noise ratio is the mean (signal) to the standard deviation (noise). Formula Ratio used to compute the S/N ratio adopted the objective function. Focusing on the strength characteristic, standard $\mathrm{S} / \mathrm{N}$ equation used the objective function was 'larger the better'. Compressive strength and impact resistance are a 'larger is better' type of quality characteristic where the aim of this work is to maximize the strength. The standard $\mathrm{S} / \mathrm{N}$ ratio computing formula for this type of response is:

$$
\left(\frac{S}{N}\right)_{i}=-10 \log \left[\frac{1}{n} \sum_{j=1}^{n} \frac{1}{Y_{i j}^{2}}\right] \ldots . e q(1)
$$

V-funnel is a 'smaller is better' function of quality characteristic since the goal is to minimize fresh properties values. The $\mathrm{S} / \mathrm{N}$ ratio standard computing formula for this response is: 


$$
\left(\frac{S}{N}\right)_{i}=-10 \log \left[\frac{1}{n} \sum_{j=1}^{n} Y^{2}\right] \ldots e q(2)
$$

Where ' $\mathrm{i}$ ' is the trial number of a; 'Yij' is the value measured of quality characteristic for the $i^{\text {th }}$ trial and $j^{\text {th }}$ experiment; ' $n$ ' is the number of repetitions for the experimental test. Signalto-noise ratios are calculated using Equation (1) for each condition of compressive strength and impact resistance. The factor can be affected separately in terms of $\mathrm{S} / \mathrm{N}$ ratio. The analysis of variance (ANOVA) is also performed to study the relative significance of the process parameters. The contributions of the various parameters are quantified.

\subsection{Fresh Properties}

The ability of SCRC to fill molds in the fresh state is defined by flowability, viscosity, passing ability, and segregation resistance. Each of them can be examined by a different test methods [13]. Flowabilityis measured using slump flow test, viscosity is measured using V-funnel flow time tests.

Self-compacting concrete requirements in fresh phase should be selected from one of the above mentioned characteristics and specified in a known value. To define the flowability, viscosity, passing ability, and segregation resistance of the produced SCRC, slump flow diameter and V-funnel flow time of the all produced concretes were measured and presented.

\subsubsection{Slump Flow Test}

Signal to noise ratios values for slump flow test are shown in table (6) and fig. (4). Table (7) shows the analysis of variance for this test. Increasing rubber content decreased slump flow diameter but increasing fly ash and/or viscocrete increased slump flow diameter. Added fly ash to the mix increased cement paste volume, which made the mix more flowable. Viscocrete increased the viscosity of concrete which increased the slump flow diameter.

Table 6: Response of Signal to Noise Ratios for slump flow (larger is better)

\begin{tabular}{|l|l|l|l|l|}
\hline Level & Fine rubber $(\mathrm{A})$ & Course rubber $(\mathrm{B})$ & Fly ash (C) & Viscocrete (D) \\
\hline 1 & 57.30 & 56.81 & 56.08 & 56.40 \\
\hline 2 & 56.92 & 56.87 & 56.33 & 56.20 \\
\hline 3 & 55.88 & 56.27 & 56.58 & 56.58 \\
\hline 4 & 55.76 & 55.91 & 56.87 & 56.69 \\
\hline Delta & 1.54 & 0.96 & 0.78 & 0.49 \\
\hline Rank & 1 & 2 & 3 & 4 \\
\hline
\end{tabular}

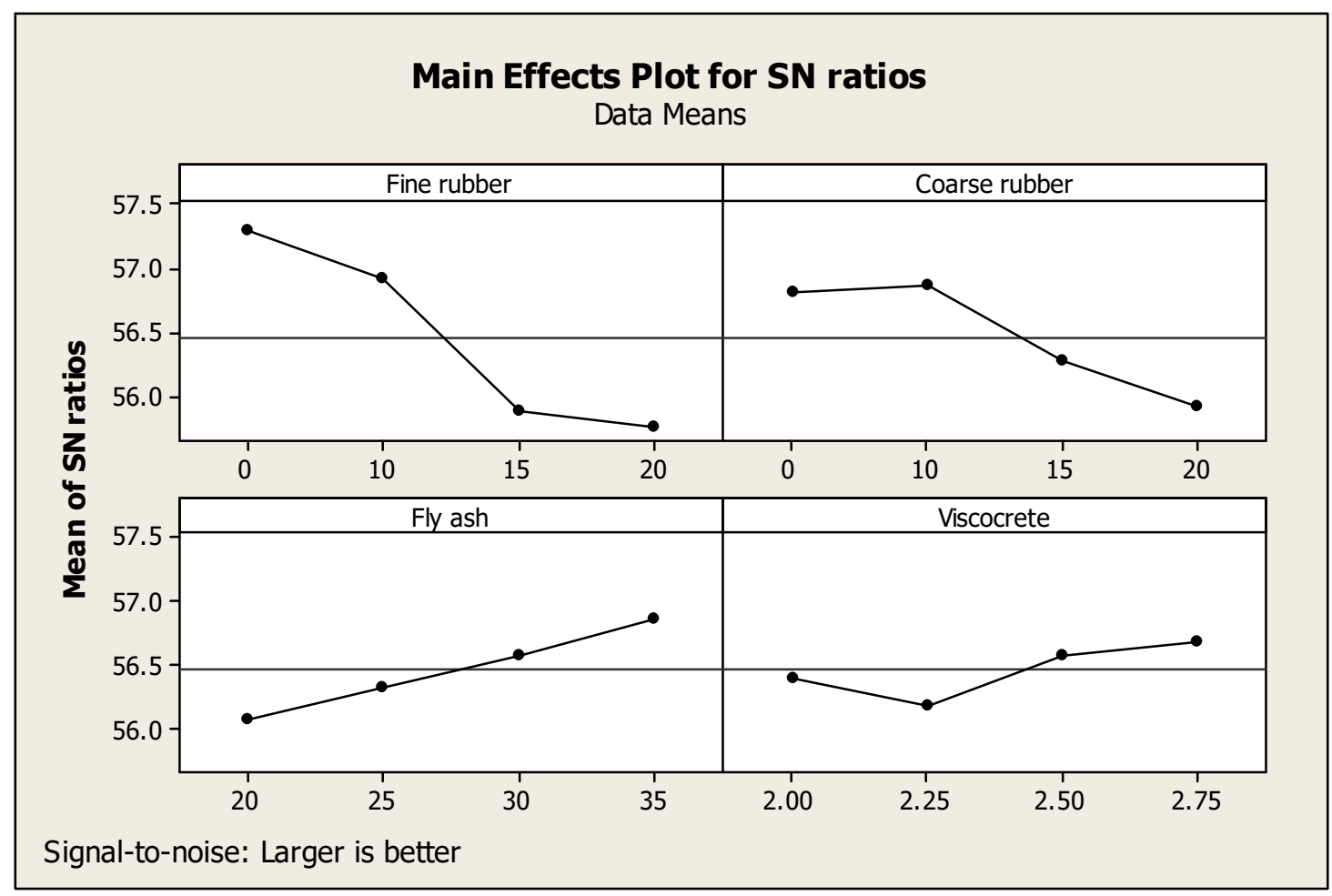

Fig 4: Main Effect Plot for Signal to Noise Ratio of slump flow (larger is Better) 
Table 7: Analysis of Variance for slump flow test, using Adjusted SS for Tests

\begin{tabular}{|l|l|l|l|l|l|}
\hline Source & DF & Seq SS & Adj SS & Adj MS & Contribution \% \\
\hline Fine rubber & 3 & 40344.9 & 40344.9 & 13448.3 & 61.27 \\
\hline Coarse rubber & 3 & 13407.4 & 13407.4 & 4469.1 & 20.36 \\
\hline Fly ash & 3 & 6557.4 & 6557.4 & 2185.8 & 9.96 \\
\hline Viscocrete & 3 & 3182.4 & 3182.4 & 1060.8 & 4.83 \\
\hline Error & 3 & 2344.9 & 2344.9 & 781.6 & 3.56 \\
\hline Total & 15 & 65837.1 & & & 100 \\
\hline
\end{tabular}

\subsubsection{V-Funnel Test}

As mentioned above, V-Funnel test is measuring the viscosity like T50 test. But here, viscocrete has 2nd rank in $\mathrm{S} / \mathrm{N}$ analysis which mean that it has a big effect on V-Funnel test. However, using the highest content of viscocrete
$(2.75 \%)$ increased the time of this test as shown in fig. (5). like T50, increasing rubber content increased V-Funnel time. Signal to noise ratio values of the control factors for this test are shown in table (8) and fig. (5). Table (9) shows the analysis of variance for this test.

Table 8: Response of Signal to Noise Ratios for V-funnel (smaller is better)

\begin{tabular}{|l|l|l|l|l|}
\hline Level & Fine rubber $(\mathrm{A})$ & Course rubber $(\mathrm{B})$ & Fly ash $(\mathrm{C})$ & Viscocrete $(\mathrm{D})$ \\
\hline 1 & -12.52 & -16.94 & -17.79 & -18.03 \\
\hline 2 & -16.23 & -16.24 & -19.45 & -16.93 \\
\hline 3 & -22.19 & -19.42 & -17.48 & -16.33 \\
\hline 4 & -20.20 & -18.54 & -16.42 & -19.85 \\
\hline Delta & 9.67 & 3.17 & 3.03 & 3.51 \\
\hline Rank & 1 & 3 & 4 & 2 \\
\hline
\end{tabular}

\section{Main Effects Plot for SN ratios} Data Means

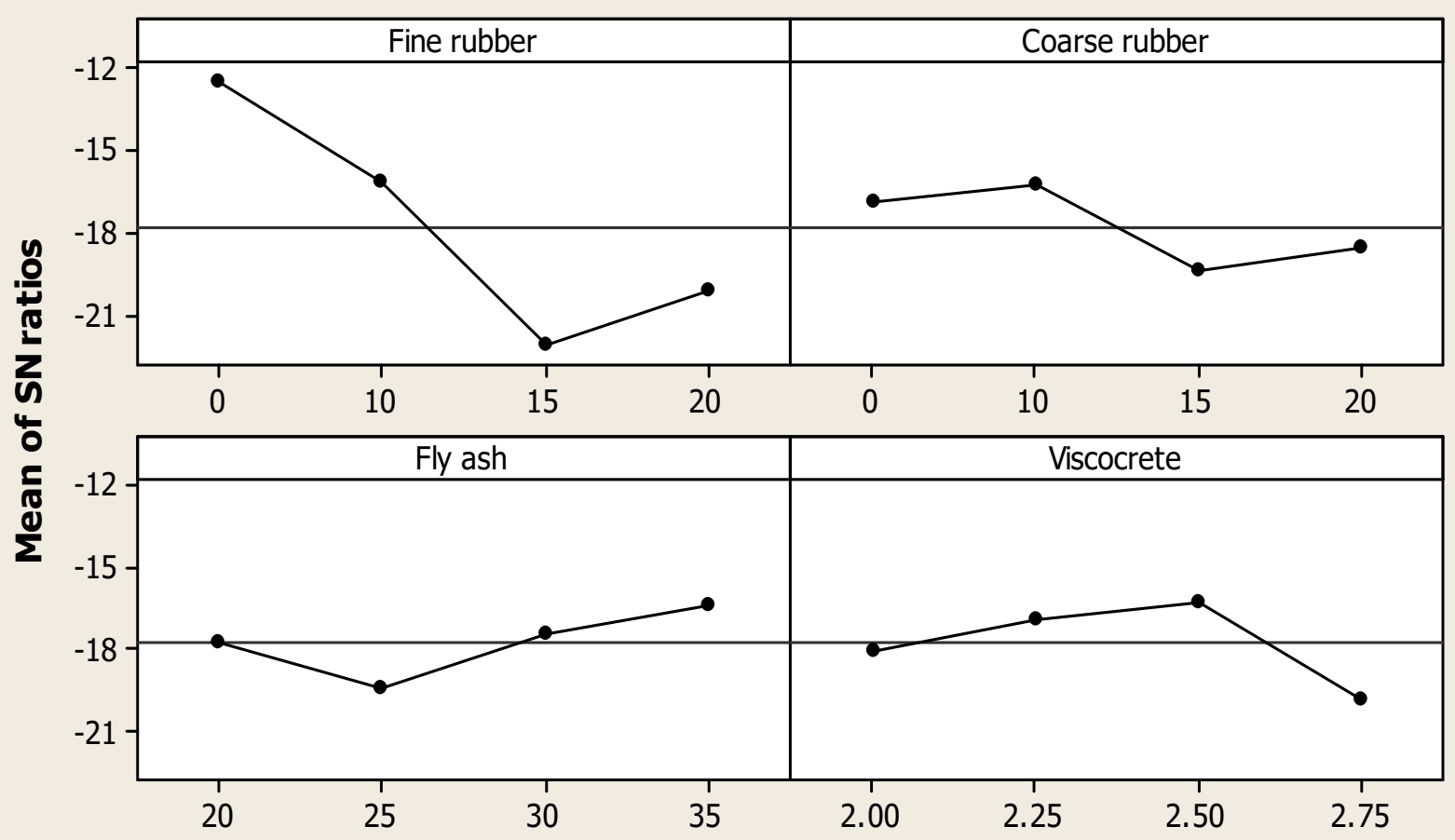

Signal-to-noise: Smaller is better

Fig 5: Main Effect Plot for Signal to Noise Ratio of V-funnel results (smaller is Better) 
Table 9: Analysis of Variance for V-Funnel test, using Adjusted SS for Tests

\begin{tabular}{|l|l|l|l|l|l|}
\hline Source & DF & Seq SS & Adj SS & Adj MS & Contribution \% \\
\hline Fine rubber & 3 & 209.952 & 209.952 & 69.984 & 59.57 \\
\hline Coarse rubber & 3 & 46.302 & 46.302 & 15.434 & 13.13 \\
\hline Fly ash & 3 & 39.520 & 39.520 & 13.173 & 11.21 \\
\hline Viscocrete & 3 & 33.017 & 33.017 & 11.006 & 9.36 \\
\hline Error & 3 & 23.628 & 23.628 & 7.876 & 6.70 \\
\hline Total & 15 & 352.419 & & & 100 \\
\hline
\end{tabular}

\subsection{Hardened Properties}

Three tested values average at 28 days was recorded to determine the compressive and impact resistance for all mixtures.

\subsubsection{Compressive Strength}

Increasing rubber content decreased the compressive strength. The decrease in compressive strength is attributed to low rubber modulus of elasticity (E), increased porosity due to air entrainment from rubber particles, and weak bond in the transition zone between cement paste and rubber particles. This weakness may be due to crack initiation from the voids generated between crumb rubber particles and cement paste. Aggregate is capable of pullout resulting in particle perimeter voids and crack initiation under compressive load. For fly ash, increasing fly ash content increased compressive strength as it works as a filler which fills the voids on concrete. Using $35 \%$ of fly ash as addition to the mix gave highest compressive strength. Viscocrete has small effect on compressive strength. It had the 4th rank in $\mathrm{S} / \mathrm{N}$ analysis. Superplasticizer added in SCC gives high strength in early age. The average values of Signal to noise ratios of compressive strength for control factors test are shown in table (10) and fig. (6). Table (11) shows the analysis of variance for this test.

Table 10: Response of Signal to Noise Ratios for Compressive Strength of 28 days (larger is better)

\begin{tabular}{|l|l|l|l|l|}
\hline Level & Fine rubber $(\mathrm{A})$ & Coarse rubber $(\mathrm{B})$ & Fly ash $(\mathrm{C})$ & Viscocrete (D) \\
\hline 1 & 52.62 & 51.93 & 49.66 & 49.98 \\
\hline 2 & 50.57 & 51.04 & 50.65 & 50.60 \\
\hline 3 & 48.98 & 49.43 & 49.50 & 50.12 \\
\hline 4 & 48.46 & 48.23 & 50.82 & 49.94 \\
\hline Delta & 4.15 & 3.70 & 1.32 & 0.66 \\
\hline Rank & 1 & 2 & 3 & 4 \\
\hline
\end{tabular}

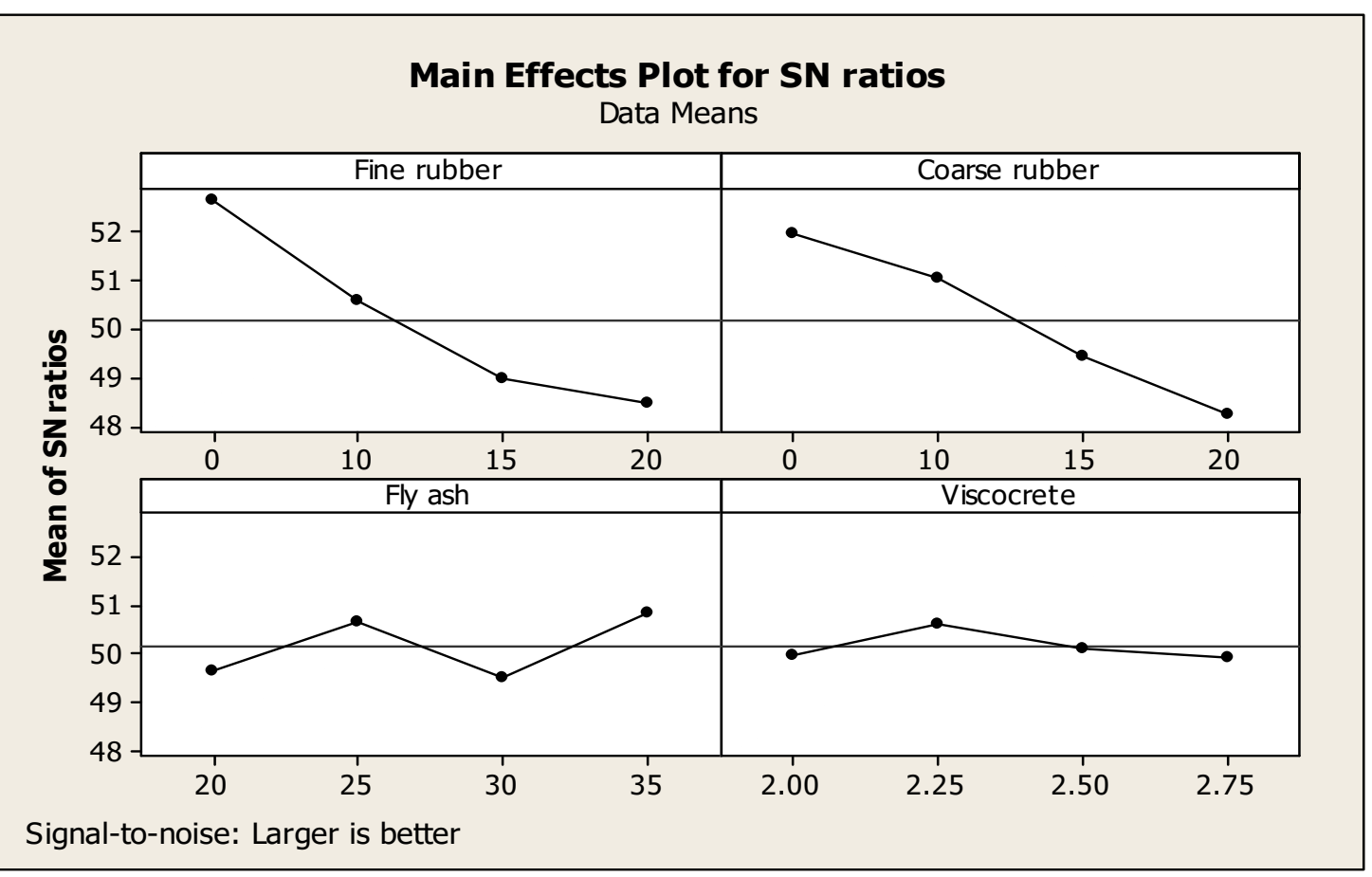

Fig 6: Main Effect Plot for Signal to Noise Ratio of Compressive Strength after 28 days (Larger is Better) 
Table 11: Analysis of Variance for 28 days Compressive Strength, using Adjusted SS for Tests

\begin{tabular}{|l|l|l|l|l|l|}
\hline Source & DF & Seq SS & Adj SS & Adj MS & Contribution \% \\
\hline Fine rubber & 3 & 65266 & 65266 & 21755 & 52.098 \\
\hline Coarse rubber & 3 & 46506 & 46506 & 15502 & 37.12 \\
\hline Fly ash & 3 & 8413 & 8413 & 2804 & 6.71 \\
\hline Viscocrete & 3 & 3273 & 3273 & 1091 & 2.61 \\
\hline Error & 3 & 1818 & 1818 & 606 & 1.45 \\
\hline Total & 15 & 125275 & & & 100 \\
\hline
\end{tabular}

\subsubsection{Impact Resistance}

Increasing rubber content led to increase impact resistance. The impact resistance, as a number of blows, increased from 17 blows for mix No.1 (no rubber replacement) to 77 blows for mix No.16 (20\% fine rubber and $20 \%$ coarse rubber). This gain of impact resistance of SCRC is due to the ability of rubber to absorb the plastic energy, which was generated from the falling of a mass from a certain height. In addition, the high deflection of the rubberized concrete increases the ability to withstand more energy. Table (12) and fig. (7) Show the average values of $\mathrm{S} / \mathrm{N}$ ratios of the control factors for T50 test. Analysis of variance (ANOVA) for experimental test is shown in table (13).The percentage of fine rubber replacement was the most significant parameter influencing the impact resistance. The percentage contribution was $75.14 \%$.

Table 12: Response of Signal to Noise Ratios for Impact Resistance after 28 days (Larger is better)

\begin{tabular}{|l|l|l|l|l|}
\hline Level & Fine rubber $(\mathrm{A})$ & Coarse rubber $(\mathrm{B})$ & Fly ash $(\mathrm{C})$ & Viscocrete $(\mathrm{D})$ \\
\hline 1 & 23.06 & 27.01 & 29.99 & 29.09 \\
\hline 2 & 28.24 & 28.11 & 28.82 & 27.70 \\
\hline 3 & 28.57 & 28.96 & 28.45 & 28.69 \\
\hline 4 & 34.35 & 30.15 & 26.97 & 28.75 \\
\hline Delta & 11.29 & 3.14 & 3.03 & 1.39 \\
\hline Rank & 1 & 2 & 3 & 4 \\
\hline
\end{tabular}

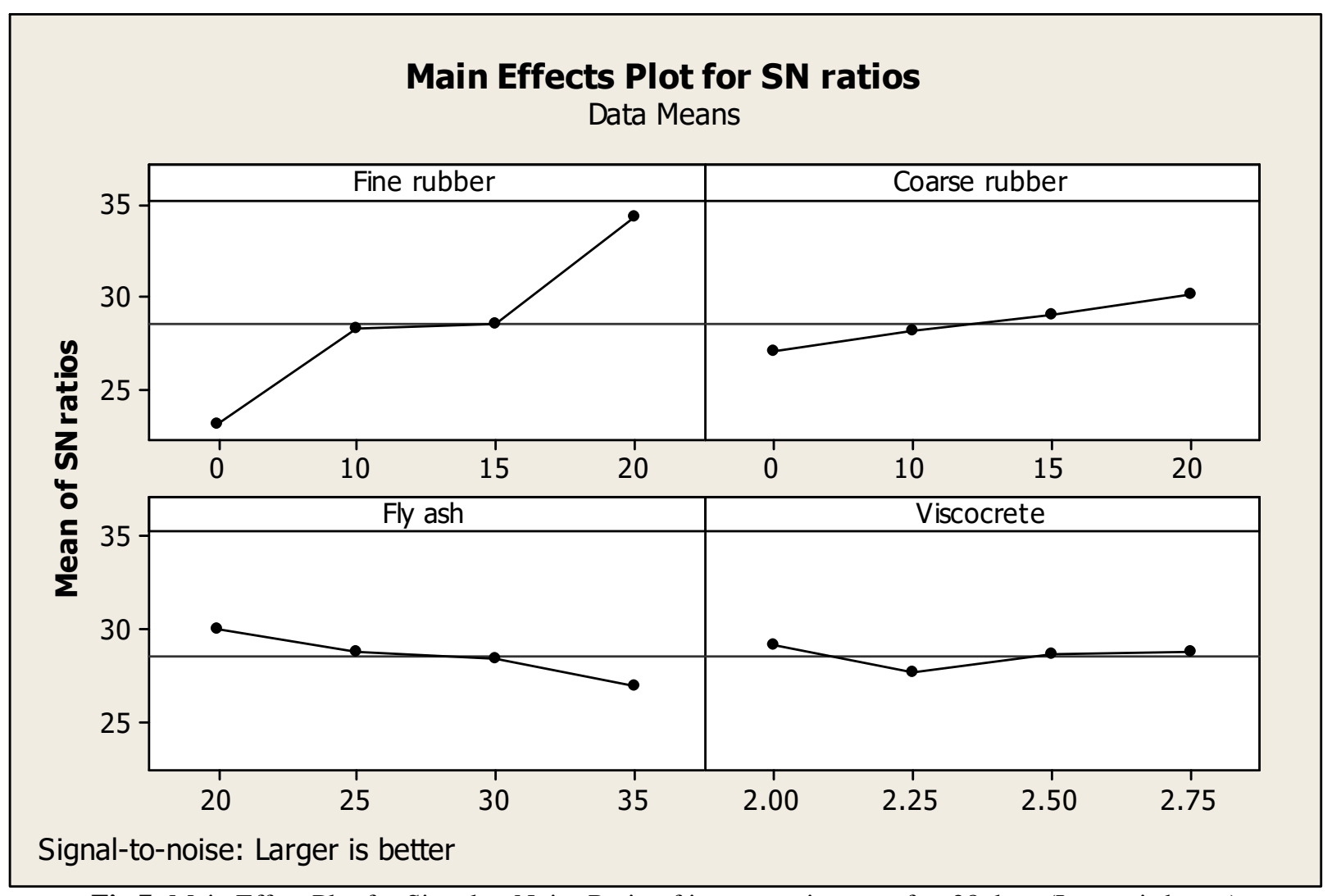

Fig 7: Main Effect Plot for Signal to Noise Ratio of impact resistance after 28 days (Larger is better) 
Table 13: Analysis of Variance for 28 days impact resistance, using Adjusted SS for Tests

\begin{tabular}{|l|l|l|l|l|l|}
\hline Source & DF & Seq SS & Adj SS & Adj MS & Contribution \% \\
\hline Fine rubber & 3 & 3514.35 & 3514.35 & 1171.45 & 75.14 \\
\hline Coarse rubber & 3 & 467.47 & 467.47 & 155.82 & 10 \\
\hline Fly ash & 3 & 443.13 & 443.13 & 147.71 & 9.47 \\
\hline Viscocrete & 3 & 146.41 & 146.41 & 48.80 & 3.13 \\
\hline Error & 3 & 105.24 & 105.24 & 35.08 & 2.25 \\
\hline Total & 15 & 4676.60 & & & 100 \\
\hline
\end{tabular}

\section{PREDICTION OF PROPERTIES}

\section{CHARACTERISTIC}

The predicted mean of the quality characteristic for slump flow, V-Funnel, compressive strength and impact resistance is computed using the following equation:

$$
\begin{gathered}
S_{m p}=\bar{Y}+\left(\bar{A}_{0}-\bar{Y}\right)+\left(\bar{B}_{0}-\bar{Y}\right)+\left(\bar{C}_{0}-\bar{Y}\right)+\left(\bar{D}_{0}-\bar{Y}\right) \\
+\left(\bar{E}_{0}-\bar{Y}\right)
\end{gathered}
$$

It is the grand average of performance characteristic.

$$
\left(\overline{A_{0}}-\bar{Y}\right),\left(\bar{B}_{0}-\bar{Y}\right),\left(\bar{C}_{0}-\bar{Y}\right),\left(\bar{D}_{0}-\bar{Y}\right) \text { and }\left(\bar{E}_{0}-\bar{Y}\right)
$$

The following values of factors were chosen: $\mathrm{A}=20 \%$, $\mathrm{B}=20 \%, \mathrm{C}=35 \%, \mathrm{D}=2.75 \%$

From the analysis of $\mathrm{S} / \mathrm{N}$ ratio and the mean response characteristic, the mean values for SCRC have been predicted as shown in table (14).

Table 14: Taguchi predicted values and actual values for SCRC.

\begin{tabular}{|l|l|l|l|}
\hline Test & $\begin{array}{l}\text { Experimental results of the } \\
\text { confirmation mix }\end{array}$ & $\begin{array}{l}\text { Taguchi predicted } \\
\text { value }\end{array}$ & $\begin{array}{l}\text { Ratio of predicted value } \\
\text { and actual value }\end{array}$ \\
\hline Slump flow & $645 \mathrm{~mm}$ & $618.28 \mathrm{~mm}$ & $95.85 \%$ \\
\hline V-funnel & 10.224 seconds & 11.0663 seconds & $108.31 \%$ \\
\hline Compression & $19.34 \mathrm{MPa}$ & $20.1 \mathrm{MPa}$ & $96.23 \%$ \\
\hline Impact & 51 blows & 55 blows & $107.85 \%$ \\
\hline
\end{tabular}

A confirmation mix was performed with the selected factors $(\mathrm{A}=20 \%, \mathrm{~B}=20 \%, \mathrm{C}=35 \%, \mathrm{D}=2.75 \%)$ and the results were recorded in table (14). These results were compared with the predicted values, illustrated in table (14), which obtained from Minitab program. The ratio between the actual values and the predicted values are also illustrated in table (14) which is in range of $10 \%$ difference so experimental results could be confirmed.

\section{CONCLUSION}

Taguchi Method achieved a good prediction of mechanical properties of self-compacting rubberized concrete in terms of compressive strength and impact resistance and fresh properties in terms of slump flow diameter and V-Funnel time. The analysis shows that the proposed Taguchi technique was adequate to predict the above properties.

The study also considered examining the influence of different concrete mix proportioning parameters that included fine rubber, coarse rubber, fly ash and viscocrete contentson the studied mechanical and fresh properties.

The analysis of variance (ANOVA) showed that the percentage of fine rubber replacement was the most significant parameter influencing the studied mechanical and fresh properties. The percentage contribution was $61.3 \%$, $59.6 \%, 52.1 \%$ and $75.14 \%$ for slump flow diameter, V-
Funnel, compressive strength and impact resistance respectively.

\section{REFERENCES}

[1]. Taha, M.M, El-Dieb, A. S., Abd El-Wahab, M. A.,and Abdel-Hameed, M. E., (2008) "Mechanical, fracture, and microstructural investigations of rubber concrete" Journal of Materials in Civil Engineering, 20(10):640-649.

[2]. Ouchi, M. and H. Okamura, (2003), "Self- Compacting Concrete" Journal of Advanced concrete Technology, 1(1):515.

[3]. Ouchi, M. and H. Okamura, (1999) "Self-compacting concrete. Development, present use and fucture" First International RILEM stmposuim on Self-compacting Concrete, 13-15 September, Stockholm: 3-14.

[4]. Bignozzi, M.C. and Sandrolini, F., (2006) "Tyre rubber waste recycling in self-compacting concrete" Cement and Concrete Research, 36(4): 735-739.

[5]. Najim, K.B. and Hall, M.R., (2012) "Mechanical and dynamic properties of self-compacting crumb rubber modified concrete" Construction and Building materials, 27(1):521-530.

[6]. M. Mishra and K.C. Panda, (2015) "Influence of Rubber on Mechanical Properties of Conventional and SelfCompacting Concrete" ITER, SOA University, Bhubaneswar 751 030, Odisha, India. 
[7]. Khalil E., Abd-Elmohsen M., Anwar M.A. (2015) "Impact Resistance of Rubberized Self-Compacting Concrete" Construction Research Institute, National Water Research Center, Delta Barrage 13621, Egypt.

[8]. Erhan, G., (2010) “Fresh properties of self-compacting rubberized concrete incorporated with fly ash" Materials \& Structures, 43:1037-1048.

[9]. Ghazy M. F., (2012), "Effect of Using Mortar Interface and Overlays in Masonry Behavior by Using Taguchi Method" ACI Materials Journal, title no. 109-M49

[10]. Ghazy M. F., (2015) "Optimization of Lightweight Concrete Process by Gray Taguchi Method" ACI Materials Journal, title no. 112-M34.

[11]. Zahran M. A. andNasser A. A., (2014) "Recycling of cement dust for manufacturing cement bricks" The 7th Int. Conf. for Develop. and the Env . in the Arab world, March, 23-25,

[12]. PhD Thesis,Najim, K.B., (2012) "Determination and Enhancement of Mechanical and Thermo-physical Behavior of Crumb Rubber-modified Structural Concrete", The University of Nottingham.

[13]. EFNARC (2005) "The European Guidelines for selfcompacting concrete: specification, production, and use" http://www.efnarc.org/ (Accessed on November 2011).

[14]. Master thesis, Eid F. M., (2003) "Properties and Fields of Application of Rubberized Concrete", Menofiya University, Egypt.

[15]. Taha, M.R., El-Dieb A., Abd El-Wahab M., (2003) "Fracture toughness of concrete incorporating rubber tire particles" International Conference on Performance of Construction Materials, a new era of building, 18-20 February, Cairo, Egypt.

[16]. Najim, K.B. and Hall, M.R., (2012) "Experimental validation of plain/self-compacting rubberized concrete (PRC/ SCRC) mix designs for structural applications" Accepted in: 14th International Conference of Structural Faults+Repair, 3-5 of July 2012: Edinburgh, Scotland, UK. 